\title{
Formation and Elimination of Pollutant during Sludge Decomposition in the Presence of Cement Raw Material and Other Catalysts
}

\author{
Juan A. Conesa, Araceli Gálvez, Ignacio Martín-Gullón, Rafael Font \\ Department of Chemical Engineering, University of Alicante, Alicante, Spain \\ E-mail:ja.conesa@ua.es \\ Recieved January 28, 2011; revised March 25, 2011; accepted May 12, 2011
}

\begin{abstract}
The use of a waste-based secondary fuel in clinker kilns is a widely used practice. Nevertheless, specific studies to understand the destruction mechanism of exhaust pollutants in cement raw material (CRM) are limited. This work focuses on the possible catalytic effect of the interaction of exhaust gases from the combustion of sewage sludge with various solids beds, including CRM. Catalyst based on vanadium pentoxide and deNO ${ }_{x}$ commercial catalyst, based on $\mathrm{Ti} / \mathrm{Zr} / \mathrm{Pt}$, were used. The behaviors of volatile compounds, polycyclic aromatic compounds and dioxins and furans are analyzed in the presence or absence of the different materials. Some compounds are produced when interacting the pollutants with the beds, and some others are destroyed. Results show that the presence of CRM at the outlet of the combustion gases is beneficial for the decrease in pollutant emission, confirmed by a catalytic effect of CRM at medium temperatures.
\end{abstract}

Keywords: Dioxin, Polycyclic Aromatic Hydrocarbons, Sewage Sludge, Cement, Emissions

\section{Introduction}

Currently, a common way of eliminating sewage sludge is its combustion in either specifically designed incinerators or in cement kilns. Incineration is the destruction by thermal oxidation at high temperature to convert waste material into a much smaller inert volume (not dangerous), i.e. the combustion of waste at high temperature in the presence of large amounts of oxygen in order to eliminate it. It can be useful to take advantage of these thermal resources while simultaneously eliminating waste. This is the case in using waste as an alternative fuel or energy recovery in industrial boilers and furnaces of clinker in the cement industry [1].

The use of alternative fuels has been an established practice in most developed countries for over the last thirty years. This is an activity being developed in Europe with total environmental quality since 1975 . This activity has both societal and industrial benefits, such as decreasing non-renewable fossil fuel consumption, lowering the emission of greenhouse gases $(75 \%$ of greenhouse gases emissions produced from waste management are due to methane generated in land filling), reducing the amount of waste deposited in landfills, recovering latent energy contained in waste and the reduction of indirect energy costs arising from the use of fossil fuels (payment of allowances for $\mathrm{CO}_{2}$ ).

In 2007, the use of alternative fuels from treated biomass in Spain reduced atmospheric $\mathrm{CO}_{2}$ emissions by 300,000 tonnes, equivalent to the emissions of 100,000 cars in one year. The average unit emissions in Spain in 2005-2006 were $860 \mathrm{~kg} \mathrm{CO}_{2} / \mathrm{t}$ clinker against the European average of $872 \mathrm{~kg} \mathrm{CO}_{2} / \mathrm{t}$ clinker and the world average of $873 \mathrm{~kg} \mathrm{CO}_{2} / \mathrm{t}$ clinker [2].

In Spain, approximately one third of installed cement furnaces are using alternative fuels, equivalent to a consumption of 3 million tonnes of coal. In 2001, the Spanish cement sector managed almost 52,000 tonnes of waste as alternative fuels, accounting for just over $1 \%$ of the theoretical consumption of clinker kilns. However, in recent years a significant increase has been realized. In 2007, more than 290,000 t of waste was managed [2]. Nevertheless, absolute amounts are still very small: $72000 \mathrm{t}$ of liquid wastes (oils, solvents, ...); 223,000 t of solid fuels as meat meal $(88,000 \mathrm{t})$, tires $(42,000 \mathrm{t})$, sawdust (35,000 t), wood (27,000 t), WWTP sludge (9000 t), 
lightweight plastic (5000 t) and lesser amounts of other waste types. This represents $8 \%$ of total fuel used in 2006, but indicating a significant increase in 5 years.

In recent literature $[3,4]$ it is shown that while the use of sewage sludge as secondary fuel is beneficial for the reduction in greenhouse gas emissions, no additional health risks for the population derived from PCDD/F and metal emissions are estimated. Concerning the properties of the clinker produced by using sludge as fuel, several research groups are working on the properties of the cement (clinker) when mixed with different wastes' ash. In literature [5] it is shown that the inclusion of ash improve mechanical properties and that mortars fabricated with $10 \mathrm{wt} \%$ sewage sludge ash replacement meet the mechanical requirements of the European standard in terms of early age compressive strength and nominal compressive strength.

\section{Precedence}

It is well known that cement kiln exhaust gases are normally clean, and no gas washing processes are necessary. In regular cement plant schemes, the cement raw material (CRM) is fed to the kiln at the opposite end to the main burner. Combustion gases, together with clinkerization exhaust gases, flow through the whole process counter-currently to solids. This disposition allows a direct contact between the fresh CRM with exhaust gases in a cyclone system, preheating CRM prior to the kiln entrance, thus saving energy. During the cooling of the exhaust gases some pollutants could be produced, such as dioxins by de-novo synthesis [6-8] or other organic compounds from the desorption on CRM $[9,10]$. Additionally, during the contact of flue gas-CRM in the cyclones, the elimination of the pollutants could also be possible by the action of CRM through adsorption or catalytic oxidation. There are many papers about the study of the adsorption of organic pollutants in different substances like fly ash, coke or active carbon [11,12] where PCDD/Fs are adsorbed up to $90 \%$, but unfortunately, there are not enough scientific references to analyze this fact over other materials.

Several works [13-17] report that a catalyst based on $\mathrm{V}_{2} \mathrm{O}_{5} / \mathrm{WO}_{3}$ supported on $\mathrm{TiO}_{2}$ produced a sharp decrease of organochlorinated compounds, including dioxins and furans $(\mathrm{PCDD} / \mathrm{Fs})$ at low temperatures $\left(200^{\circ} \mathrm{C}-400^{\circ} \mathrm{C}\right)$. This catalyst is commercially available due to its being commonly used in the SCR process for the elimination of $\mathrm{NO}_{\mathrm{x}}$ of flue gas stream $\left(\mathrm{DeNO}_{\mathrm{x}}\right)$. Some researchers [17, 18] carried out experiments with a $\mathrm{V}_{2} \mathrm{O}_{5} / \mathrm{TiO}_{2}$ cata- lyst in relation to PAHs and found that the efficacy for PAHs destruction increases with temperature and the efficacy for PAHs adsorption on the catalyst pellets decreases. With respect to dioxin elimination, some papers have been published on this subject [12,17-21]. The re- sults of these studies revealed that the use of $\mathrm{V}_{2} \mathrm{O}_{5} / \mathrm{TiO}_{2}$ catalysts results in a decrease of PCDD/Fs emissions of $90 \%$ - $99 \%$ at $200^{\circ} \mathrm{C}-300^{\circ} \mathrm{C}$. According to [17], the elimination of dioxins is $98 \%$ at $230^{\circ} \mathrm{C}$ with $1 \%$ adsorption on the catalyst. On the other hand, it has been shown that the adsorption decreases with temperature [18].

In the work presented in this paper, the direct contact of a stream of gases produced during combustion of sewage sludge with a fixed bed of different materials was considered. The analysis of the volatile compounds, semivolatile (PAHs) and dioxins and furans resulting in emissions was recorded, in order to analyze the effect of the presence of the different particle beds. This study was conducted in two stages. First, a few preliminary experiments were conducted in the laboratory furnace described elsewhere [22]. In a second stage, a new experimental system was designed, with the aim to corroborate some results and to extend the study with the use of new materials and different operating conditions.

\section{Material and Methods}

Dried sewage sludge from a waste water facility in Tarragona, Spain was used. In addition, milled cement raw material (CRM), supplied by a cement industry close to the University of Alicante was also used. An exhaustive analysis of the two materials used made, and the results are shown elsewhere [22]. A previous crushing was carried out to improve homogenization.

Other materials used to directly compare the catalytic over the flue gases are:

$\mathrm{V}_{2} \mathrm{O}_{5}-1 \mathrm{wt} \%$ of vanadium pentoxide was incorporated to $\mathrm{SiO}_{2}$. It is known the catalytic activity of $\mathrm{V}_{2} \mathrm{O}_{5}$ in the removal of $\mathrm{NO}_{\mathrm{x}}$ emissions in chimneys. In recent years, it has also been proven that reduces the emission of PCDD/Fs [19].

PD-Alumina/Palladium catalyst beads with $1 \%$ of active phase provided by Enghelard.

CA-Automotive catalyst honeycomb extracted for a car muffler. Table 1 shows the metallic composition of

Table 1. Analysis of the automotive catalyst.

\begin{tabular}{cc}
\hline Oxide & Weight $\%$ \\
\hline $\mathbf{A l}$ & 26.64 \\
$\mathbf{S i}$ & 13.41 \\
$\mathbf{M g}$ & 3.61 \\
$\mathbf{L a}$ & 0.72 \\
$\mathbf{F e}$ & 0.47 \\
$\mathbf{C e}$ & 0.34 \\
$\mathbf{T i}$ & 0.26 \\
$\mathbf{Z r}$ & 0.25 \\
$\mathbf{P}$ & 0.14 \\
$\mathbf{P t}$ & 0.10 \\
\hline
\end{tabular}


this catalyst obtained by X-Ray Fluorescence, where the active metals or promoters seem to be La, Ce and Pt.

The equipment used to carry out the present work, this catalyst obtained by X-Ray Fluorescence, where the shown in Figure 1, has been exclusively developed to accurately control the ratio of oxygen in combustion processes. It consists of a moving tubular reactor with the sewage sludge carefully placed along the tube, which is introduced at a precisely controlled speed in a furnace while passing through a constant flow of air. In this way, a constant flow of air and a constant mass rate of sludge were used. This permits to simulate during several minutes the continuous combustion.

The equipment comprises a sample introduction area, the combustion zone, the gas transfer zone and the zone of interaction of gases with the different catalyst, which is separately heated by a blanket heater, simulating the gas temperature in the cyclonic system in a cement plant. Before carrying out the experiments shown in this paper, it was done a comprehensive study on the capacity of the equipment with respect to leaks, reproducibility of experiments, and homogeneity of the obtained gas flow.

The ratio between carbon monoxide and carbon dioxide is maintained in all experiments to approximately 0.38 , indicating that the combustion process has been carried out very similarly in all runs.

In the case of powdery substances, as is the case of $\mathrm{V}_{2} \mathrm{O}_{5} / \mathrm{SiO}_{2}$ catalyst, quartz wool was intercalated in order to reduce pressure drop. The mass ratio between the amount of sludge used in each experiment and the catalyst was 4: 1.

During the study, several operating conditions were modified, such as temperature and catalyst nature. Oxygen ratio, as defined by [23], was kept constant at $\lambda=$ 0.14 , a sub-stoichiometric value in order to simulate poor areas and poor combustion furnace mixing and therefore mass production of organic contaminants. To achieve these combustion conditions, a sample size of approximately $1200 \mathrm{mg}$ spread over $280 \mathrm{~mm}$ was used. The sample introduction rate was $1.8 \mathrm{~mm} / \mathrm{s}$ and the air flow was $300 \mathrm{ml} / \mathrm{min}$. The temperatures were $850^{\circ} \mathrm{C}$ in the combustion oven and $300^{\circ} \mathrm{C}$ in the transfer and interacttion-catalyst line. The particles used in the interaction zone were introduced into tubes of $8 \mathrm{~mm}$ internal diameter and along the length $10-15 \mathrm{~mm}$.

Comparing these experimental conditions with that present in the cement plant, it is interesting to note that the temperature in the lab reactor is much lower than that of the plant. Furthermore, the preheater and precalciner stage, from the flue gas, and the quenching of the hot kiln gases before air pollution treatment are not separately considered. Although the ultimate application of the study is the use of sewage sludge in cement plants, we must take into account that the conditions are not reproducing the industrial plant. The experimental conditions, with a very low air supply, are selected in order to maximize the production of pollutants such as PAHs or dioxins, as previously presented [23,24].

On the other hand, temperature of the actual interacttion of CRM with the hot gases is not known. The interaction takes place somewhere between the gas exit of the cement kiln (approx. $1500^{\circ} \mathrm{C}$ ) and the input of the meal solids (approx. $300^{\circ} \mathrm{C}$ in the preheater). In the present study an intermediate temperature of $850^{\circ} \mathrm{C}$ has been selected.

\section{Sampling}

Sampling was carried out at the end of the interaction zone. Three types of pollutants have been analyzed:

- Volatile organic compounds (C1-C6) gases were collected using Tedlar bags ${ }^{\circledR}$ and then analyzed by gas chromatograph with flame ignition detector (GC-FID) and with thermal conductivity detector (GC-TCD).

- Semivolatile organic compounds (PAHs): a XAD2 resin was used as adsorbent and after a process of extraction and concentration was analyzed by high resolution gas chromatography and spectrometry (HRGC/MS). The analysis of semivolatile compounds has focused exclusively on the group of 16 polyaromatic hydrocarbons established by the American Environmental Protection Agency (USEPA) as priority pollutants and potential carcinogens.

- Dioxins and furans: collected similarly to PAHs with subsequent analysis by HRGC/MS. Method EPA 1613 was used to analyze the samples.

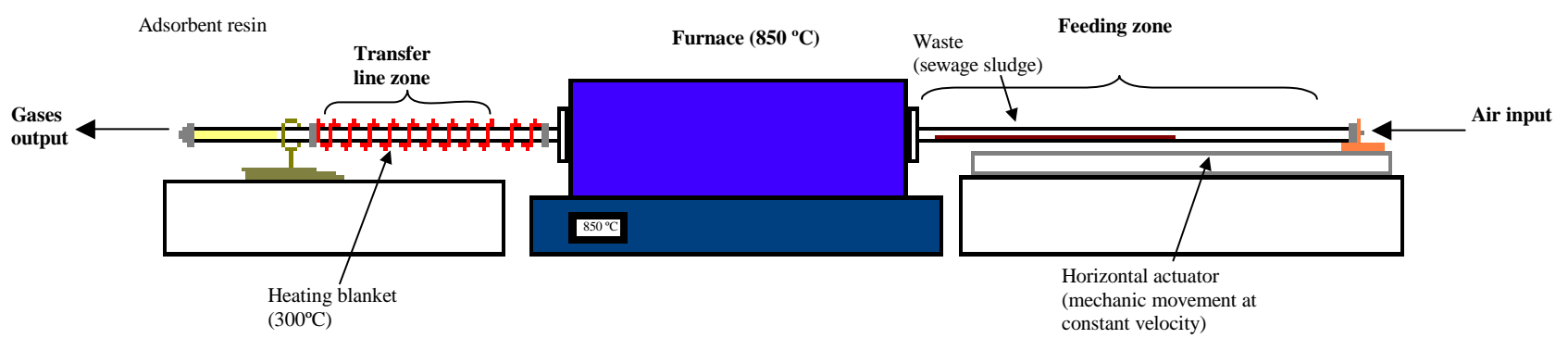

Figure 1. Scheme of the laboratory equipment used. 


\section{Results and Discussion}

\subsection{Volatile Organic Compounds (VOCs)}

VOCs analyzed in each of the conditions did not show changes in yields when using any catalyst. Figure 2 shows the results achieved with the different runs considering the sewage sludge combustion without any material in the bed and with different materials inside the bed. It can be observed that the profile of compounds in all cases is quite similar, and no specific trend can be seen in the elimination of compounds in this range of volatility.

This result coincides with that found in the preliminary runs [22] in which smaller-scale experiments already indicated that none of the substances tested caused the removal of hydrocarbons, even heavier substances such as benzene, toluene and xylenes. The main com- pounds are methane, ethylene and benzene, as already shown in the work of [24] and [22].

\subsection{Polycyclic Aromatic Hydrocarbons (PAHs)}

Table 2 shows the results for the experiments done with the different materials in the bed at the post-combustion zone. The profile of compounds is very similar in all experiments, with naphthalene, acenaphthylene, fluorene and phenanthrene as major compound in all cases, regardless of catalyst used. Considering the data, we can observe that the lightest PAHs present relative high yields. The exhaust catalysts from the bed used in the runs were also analyzed for PAHs, and virtually no adsorbed hydrocarbons were found. In this way, the power of removing this type of compounds is mainly due to thermal destruction or decay, not adsorption in the bed.

In order to analyze the experimental data, it is useful

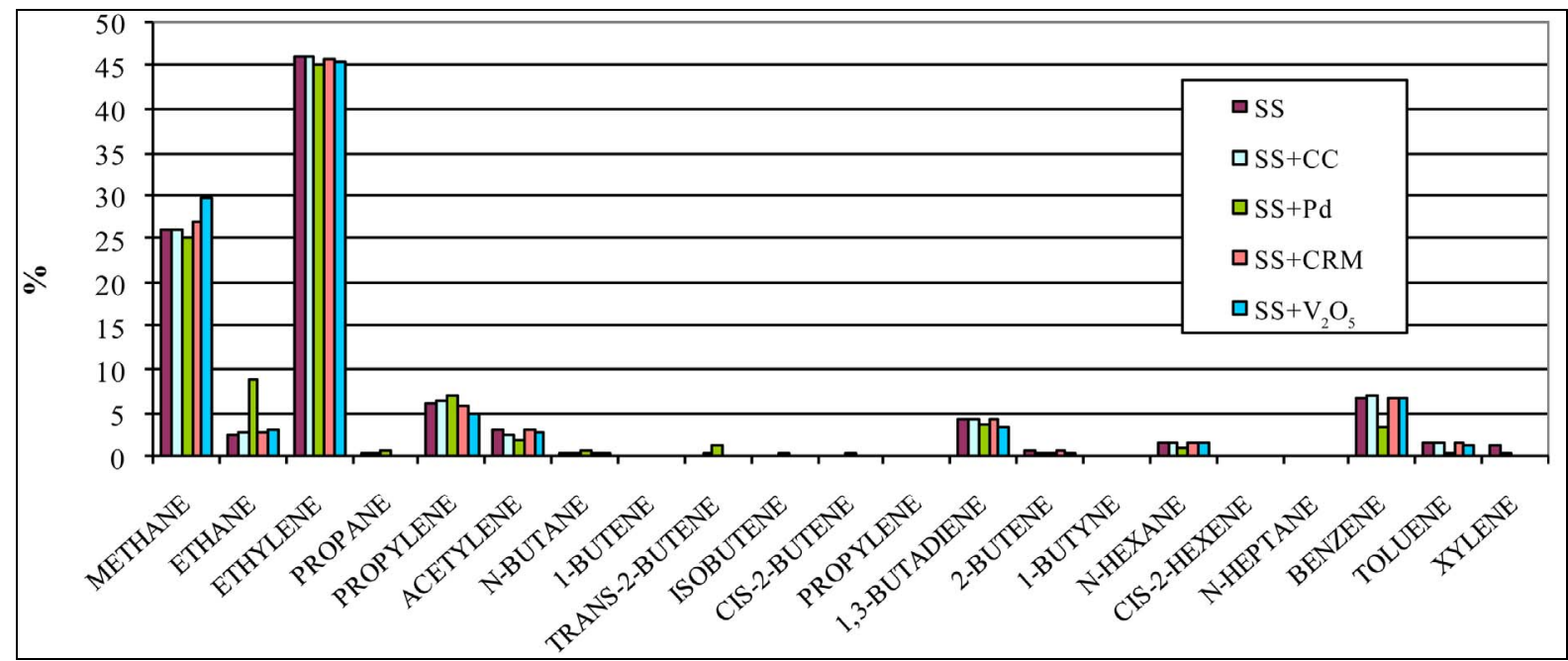

Figure 2. Emission of VOCs. SS: sewage sludge combustion; SS + CC: use of automotive honeycomb catalyst; SS + Pd: use of bead paladium catalyst; $\mathrm{SS}+\mathrm{CRM}$ : use of cement raw material; $\mathrm{SS}+\mathrm{V}_{2} \mathrm{O}_{5}$ : use of $\mathrm{Si}+\mathrm{V}_{2} \mathrm{O}_{5}$.

Table 2. Emission of PAHs.

\begin{tabular}{|c|c|c|c|c|c|c|}
\hline & MW (g/mol) & SS & $\mathbf{S S}+\mathbf{C C}$ & SS + CRM & $\mathbf{S S}+\mathbf{P d}$ & $\mathrm{SS}+\mathrm{V}_{2} \mathrm{O}_{5}$ \\
\hline Naphthalene & 128 & 2472 & 3393 & 1696 & 1393 & 1862 \\
\hline Acenaphtylene & 152 & 505 & 211 & 385 & 293 & 503 \\
\hline Acenaphtene & 154 & 39.8 & 39.7 & 24.0 & 148 & 25.1 \\
\hline Phenanthrene & 188 & 330 & 337 & 215 & 275 & 256 \\
\hline Anthracene & 188 & 99.6 & 123.3 & 75.4 & 83.5 & 107 \\
\hline Fluoranthene & 202 & 58.8 & 61.5 & 45.9 & 45.4 & 60.9 \\
\hline Benzo(a)anthracene & 228 & 12.3 & 32.7 & 20.8 & 23.8 & 32.2 \\
\hline Chrysene & 228 & 24.3 & 26.4 & 28.4 & 24.3 & 22.4 \\
\hline Benzo(b)fluoranthene & 252 & 7.5 & 11.2 & 4.2 & 5.3 & 6.2 \\
\hline Benzo(k)fluoranthene & 252 & 1.8 & 3.3 & 3.7 & 6.3 & 6.2 \\
\hline Benzo(a)pyrene & 252 & 6.5 & 12.0 & 7.2 & 9.1 & 12.7 \\
\hline Indeno $(1,2,3-c d)$ pyrene & 276 & 3.4 & 2.5 & 2.4 & 2.2 & 3.1 \\
\hline
\end{tabular}

SS = sewage sludge; CC = automotive catalyst; CRM = cement raw material; $\mathrm{Pd}$ = palladium based catalyst. 
to calculate the production percentage of each of the compounds compared with the experiment in which there is no active solid phase. The production percentage will be calculated for each PAH compound analyzed based on the equation:

$$
\begin{aligned}
& \% \text { production } \\
& =\frac{\left(\text { emited } m g-\left(m g_{\text {during sludge decomposition }}\right)\right)}{m g_{\text {during sludge decomposition }}} \times 100
\end{aligned}
$$

where $m g_{\text {during sludge decomposition }}$ represents the emission of the particular compounds with no bed in the post-combustion zone. Thus, a positive output percentage indicates a greater emission, probably due to a greater formation of that particular compound in the experiment only with sludge. The opposite will happen if we obtain a negative value, indicating in this case a greater destructtion. Figure 3 shows the results for the PAHs analysed.

One can see that the cement raw material (SS + CRM) is the material that produces fewer compounds and therefore has more activity, regardless of the PAH considered. The results using vanadium pentoxide are similar to SS + CRM, probably due to the fact that bed containing $\mathrm{V}_{2} \mathrm{O}_{5}$ is composed mostly of silica, one of the major components of cement raw material, so it must be that silica has an effect of elimination similar to crude. On the other hand, the automotive catalyst and the alumina balls lead to an increase production of some polyaromatic hydrocarbons, reaching values greater than $400 \%$ for the production of acenaphthene. The higher molecular weight compounds undergo high removal rates in all experiments.

There are many processes occurring in the catalytic bed reactor system, such as are the reactions of cracking of high molecular weight compounds giving lower molecular weight compounds as final products hydrogen and carbon [25] and pyrosynthesis reactions, which are responsible for the formation of high molecular weight compounds from smaller compounds [26,27]. The final product of these reactions is the soot.

Based on these patterns, Figure 3 shows the general behavior of the production of compounds of intermediate molecular weight, whereas both compounds with low or high MW, or are not produced, or are destroyed properly. This behavior is logical bearing in mind that, due to cracking and pyrosynthesis reactions, the lower and the higher MW compounds are producing intermediate MW compounds.

In the results obtained during the decomposition of sewage sludge by [24], this behavior is also observed, so that compounds such as acenaphthylene, phenanthrene, anthracene, and benzo (a) anthracene have maximum yields at intermediate temperatures, i.e. at intermediate cracking conditions, what indicates that these compounds are producing lower and higher molecular weight compounds. It should be kept in mind that the experimental conditions $(\lambda=0.14)$ are very close to pyrolytic conditions, which permits the catalyst to show their potential as radical generators causing the decomposition of polyaromatic hydrocarbons [28].

\subsection{Polychlorinated Dioxins and Furans (PCDD/Fs)}

The results of the analysis of dioxins and furans for each of the types of experiments are found in Table 3, which shows both the absolute concentration and that obtained by applying toxic equivalency factors and the total toxic-

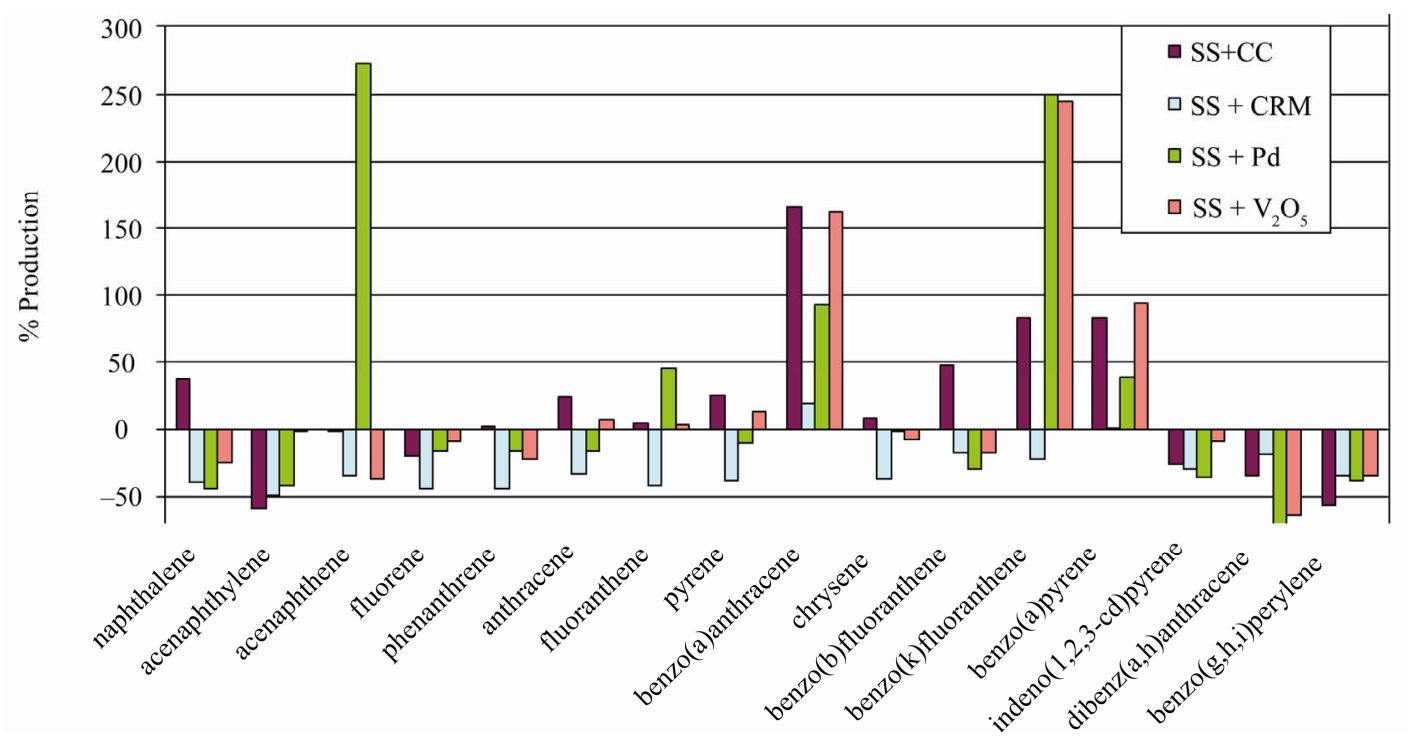

Figure 3. Percentage of production of each individual PAH. 
Table 3. Emission of PCDD/Fs.

\begin{tabular}{|c|c|c|c|c|c|c|c|c|c|c|}
\hline & \multicolumn{2}{|r|}{ SS } & \multicolumn{2}{|c|}{$\mathrm{SS}+\mathrm{CC}$} & \multicolumn{2}{|c|}{ SS + CRM } & \multicolumn{2}{|c|}{ SS + Pd } & \multicolumn{2}{|c|}{$\mathrm{SS}+\mathrm{V}_{2} \mathrm{O}_{5}$} \\
\hline & $\mathrm{pg} / \mathrm{g}$ & pg I-TEQ/g & $\mathrm{pg} / \mathrm{g}$ & pg I-TEQ/g & $\mathrm{pg} / \mathrm{g}$ & pg I-TEQ/g & $\mathrm{pg} / \mathrm{g}$ & pg I-TEQ/g & $\mathrm{pg} / \mathrm{g}$ & pg I-TEQ/g \\
\hline 2378-TCDF & 133.6 & 13.36 & 20.87 & 2.09 & 12.66 & 1.27 & 40.98 & 4.10 & 10.56 & 1.06 \\
\hline 12378-PeCDF & 75.12 & 3.76 & 46.56 & 2.33 & 30.71 & 1.54 & 68.70 & 3.44 & 103.74 & 5.19 \\
\hline 23478-PeCDF & 171.01 & 85.50 & 110.14 & 55.07 & 53.86 & 26.93 & 141.64 & 70.82 & 151.37 & 75.69 \\
\hline 123478-HxCDF & 296.38 & 29.64 & 102.11 & 10.21 & 41.42 & 4.14 & 134.97 & 13.50 & 154.20 & 15.42 \\
\hline 123678-HxCDF & 177.04 & 17.70 & 178.13 & 17.81 & 43.19 & 4.32 & 130.74 & 13.07 & 187.03 & 18.70 \\
\hline 234678-HxCDF & 262.75 & 26.28 & 155.64 & 15.56 & 68.61 & 6.86 & 130.50 & 13.05 & 295.18 & 29.52 \\
\hline 1234678-HpCDF & 852.22 & 8.52 & 584.78 & 5.85 & 199.61 & 2.00 & 345.96 & 3.46 & 833.83 & 8.34 \\
\hline 1234789-HpCDF & 78.37 & 0.78 & 41.60 & 0.42 & 6.44 & 0.06 & 46.59 & 0.47 & 100.83 & 1.01 \\
\hline OCDF & 209.79 & 0.21 & 192.57 & 0.19 & 22.97 & 0.02 & 102.85 & 0.10 & 149.38 & 0.15 \\
\hline 2378-TCDD & 7.96 & 7.96 & 12.98 & 12.98 & 7.21 & 7.21 & 2.44 & 2.44 & 83.29 & 83.29 \\
\hline 12378-PeCDD & 7.07 & 3.54 & 10.60 & 5.30 & 42.97 & 21.49 & 12.93 & 6.46 & 38.90 & 19.45 \\
\hline 123478-HxCDD & 3.95 & 0.43 & 21.53 & 2.15 & 7.21 & 0.72 & 21.87 & 2.19 & 24.02 & 2.40 \\
\hline 123678-HxCDD & 5.18 & 0.52 & 20.97 & 2.10 & 6.61 & 0.66 & 17.16 & 1.72 & 25.19 & 2.52 \\
\hline 123789-HxCDD & 4.03 & 0.40 & 23.77 & 2.38 & 8.70 & 0.87 & 27.40 & 2.74 & 27.68 & 2.77 \\
\hline OCDD & 32.78 & 0.03 & 41.53 & 0.04 & 31.43 & 0.03 & 21.30 & 0.02 & 106.48 & 0.11 \\
\hline$\%$ elimination & & & & 31.84 & & 60.61 & & 29.88 & & -35.36 \\
\hline TOTAL & & 205.45 & & 138.83 & & 80.23 & & 142.82 & & 275.71 \\
\hline$\%$ PCDD & 4.05 & 6.45 & 10.40 & 18.26 & 19.09 & 38.78 & 10.00 & 11.11 & 85.20 & 40.30 \\
\hline$\%$ PCDF & 95.95 & 93.55 & 89.60 & 81.74 & 80.91 & 61.22 & 90.00 & 88.89 & 14.81 & 59.70 \\
\hline
\end{tabular}

SS = sewage sludge; CC = automotive catalyst; CRM = cement raw material; $\mathrm{Pd}$ = palladium based catalyst.

ity. For these types of compounds there is a decrease in the toxicity that varies between $30 \%$ and $60 \%$, with the maximum removal in the presence of cement raw material. From the data, we observe an increase of over $30 \%$ with the use of $\mathrm{V}_{2} \mathrm{O}_{5}$. These behaviors are due to the decline of some selected congeners and also to a shift in the congener from more to less toxic (higher chlorinated congeners).

Regarding the distribution of dioxins and furans, in all experiments there is a profile change for dioxins, going from $6.5 \%$ to almost $40 \%$. The cement raw material and vanadium pentoxide are the substances most responsible for this effect.

To more clearly assess the emission of each congener, the production percentage has been calculated in a manner analogous to the case of PAHs. Figure 4 shows the result. It is clear from this Figure that there is a higher production of dioxins, instead of furans, and even leading to a production increase of over $500 \%$. The removal rates of furans can reach up to $100 \%$ in some congeners. Note the high levels of production found in the runs done in the presence of vanadium pentoxide in virtually all congeners; and it is remarkable that is the only bed that produces higher levels of furans. On the other hand, it is worthy to note that cement crude achieves the highest removal rates of virtually all congeners, including dioxins.

\section{Conclusions}

The use of raw cement and other substances such as beds of catalysts interacting with the flue gas of sewage sludge has had different effects depending on the nature of the materials used and the type of compounds to remove.

The concentrations of volatile compounds are unaffected by the use of any of the materials used in the beds. There is no significant change in concentration in any run.

The emission of polyaromatic hydrocarbons is characterized by the presence of naphthalene, which reaches more than $50 \%$ of the total PAHs emitted. Crude cement is the substance that has the greatest power of elimination on this compound, followed by $\mathrm{V}_{2} \mathrm{O}_{5}$, which has a very similar behavior probably because the silica is among major components of the crude cement. The CRM has a chemical composition represented by amount of oxides (mainly $\mathrm{Al}_{2} \mathrm{O}_{3}, \mathrm{CaO}, \mathrm{Fe}_{2} \mathrm{O}_{3}, \mathrm{P}_{2} \mathrm{O}_{5}, \mathrm{SiO}_{2}$ and minor amounts of $\mathrm{MgO}, \mathrm{TiO}_{2}, \mathrm{Cr}_{2} \mathrm{O}_{3}, \mathrm{ZnO}, \mathrm{CuO}$ ) that actually form different minerals. Indeed, these mineral compounds can cause reactions on the CRM surface due to their acid-basic characteristics.

The use of two commercial catalysts has not caused the desired effect in the conditions used in the present study.

As far as the emission of dioxins and furans, it is observed that the use of raw cement causes a decrease of over $60 \%$ in the toxicity of the sample due to both a change in the congener profile and a pronounced decrease in emissions. On the other hand, the use of vanadium pentoxide has caused a completely opposite behavior of that expected, the increased toxicity of the sample due to the increase of congeners of low degree of chlorination. 


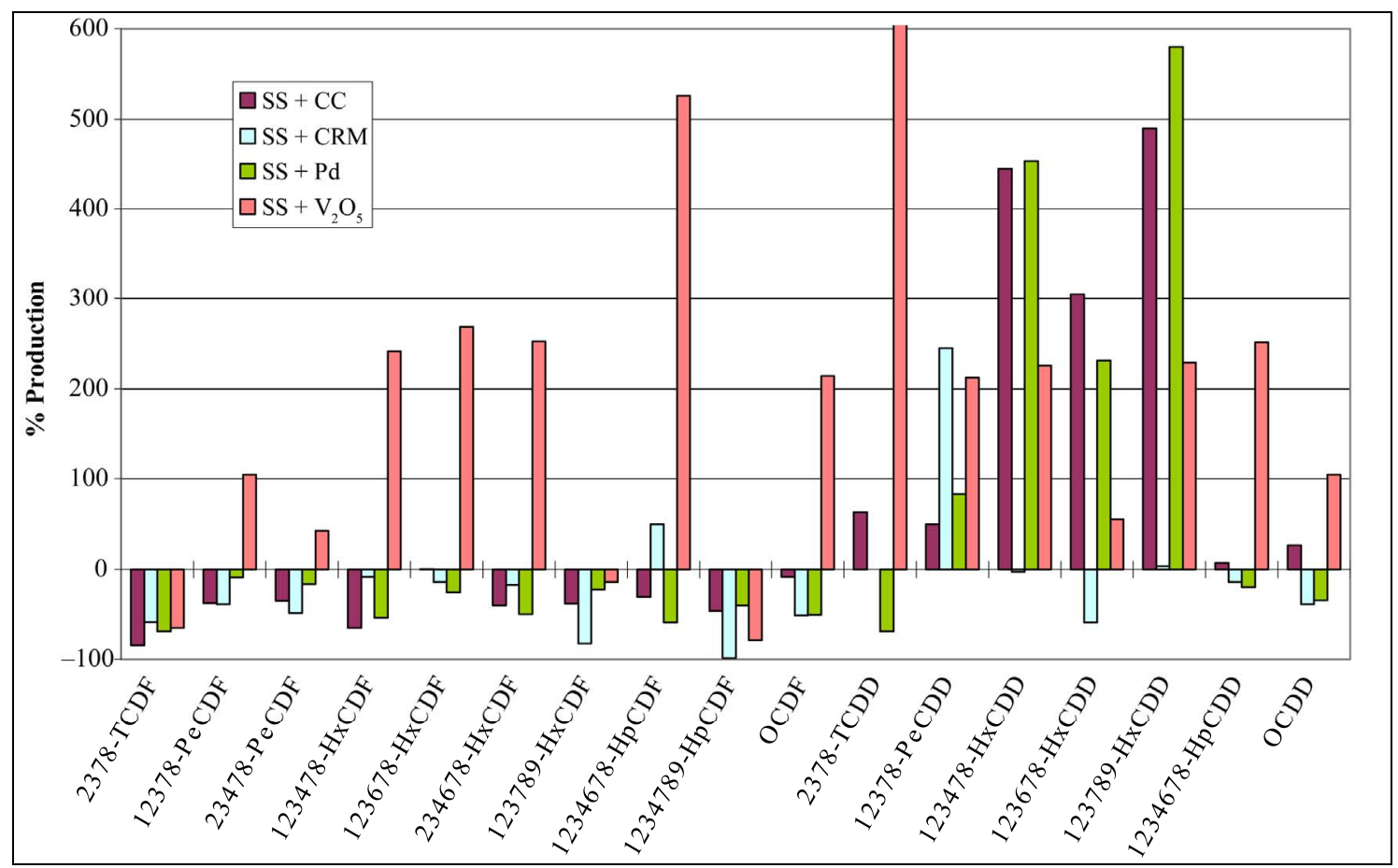

Figure 4. Percentage of production of each individual congener of PCDD/Fs.

Probably, the use of sewage sludge as alternative fuel in cement kilns does not cause an increase in organic pollutant emissions because the compounds are reduced both by the gas cleaning system and by the reactions occurring in the preheat zone of raw materials. In the cyclones, the interaction between crude cement and gases is produced, causing the elimination of a signifyncant portion of the organic contaminants that may have been produced during the combustion process of waste. For this reason, the use of sewage sludge in cement kilns is a sure alternative to manage the excess waste.

\section{Aknowledgements}

Support for this work was provided by Generalitat Valenciana (Spain) with projects Prometeo/2009/043 and ACOM2009/135, and by the Spanish MCT CTQ200805520 .

\section{References}

[1] W. D. Robinson, "The Solid Waste Handbook. A Practical Guide,” John Wiley \& Sons, Hoboken, 1986. doi:10.1002/9780470172957

[2] Oficemen, “Anuario 2008,” Agrupación de fabricantes de cemento de España, 2008.

[3] M. Nadal, M. Schuhmacher and J. L. Domingo, "CostBenefit Analysis of Using Sewage Sludge as Alternative Fuel in a Cement Plant: A Case Study,” Environmental
Science and Pollution Research, Vol. 16, No. 3, 2009, pp. 322-328. doi:10.1007/s11356-008-0063-7

[4] J. A. Conesa, A. Gálvez, F. Mateos, I. Martín-Gullón and R. Font, "Organic and Inorganic Pollutants from Cement Kiln Stack Feeding Alternative Fuels,” Journal of Hazardous Materials, Vol. 158, No. 2-3, 2008, pp. 585-592. doi:10.1016/j.jhazmat.2008.01.116

[5] P. Garcés, M. Pérez Carrión, E. García-Alcocel, J. Payá, J. Monzó and M. V. Borrachero, "Mechanical and Physical Properties of Cement Blended with Sewage Sludge Ash,” Waste Management, Vol. 28, No. 12, 2008, pp. 24952502. doi:10.1016/j.wasman.2008.02.019

[6] J. A. Conesa, A. Fullana and R. Font, "De Novo Synthesis of PCDD/F by Thermogravimetry," Environmental Science Technology, Vol. 36, No. 2, 2002, pp. 263-269. doi:10.1021/es015545n

[7] K. Everaert and J. Baeyens, "The Formation and Emission of Dioxins in Large Scale Thermal Processes," Chemosphere, Vol. 46, No. 3, 2002, pp. 439-448. doi:10.1016/S0045-6535(01)00143-6

[8] K. Everaert, J. Baeyens and J. Degrève, "Removal of PCDD/F from Incinerator Flue Gases by Entrained-Phase Adsorption," Journal of the Air and Waste Management Association, Vol. 52, No. 12, 2002, pp. 1378-1388.

[9] S. Sidhu and B. Dellinger, "PCDD/F Formation in Cement Kiln Pre-Heat Zone from Reactions of Raw Meal Hydrocarbons," International Conference on Incineration and Thermal Treatment Technologies, Phoenix, 14-18 May 1997.

[10] S. Sidhu, N. Kasti, P. Edwards and B. Dellinger, "Hazardous Air Pollutants Formation from Reactions of Raw 
Meal Organics in Cement Kilns,” Chemosphere, Vol. 42, No. 5-7, 2001, pp. 499-506. doi:10.1016/S0045-6535(00)00222-8

[11] K. Everaert, J. Baeyens and C. Creemers, “Adsorption of Dioxins and Furans from Flue Gases in an entrained Flow or Fixed/Moving Bed Reactor," Journal of Chemical Technology Biotechnology, Vol. 78, No. 2-3, 2003, pp. 213-219. doi:10.1002/jctb.752

[12] K. Everaert and J. Baeyens, "Removal of PCDD/F from Flue Gases in Fixed or Moving Bed Adsorbers," Waste Management, Vol. 24, No. 1, 2004, pp. 32-42. doi:10.1016/S0956-053X(03)00136-3

[13] G. C. Bond and S. F. Tahir, "Influence of Phosphorus and Potassium Additives on the Properties of Vanadia/Titania Catalysts," Catalysis Today, Vol. 10, No. 3, 1991, pp. 393-395. doi:10.1016/0920-5861(91)80021-Z

[14] S. Krishnamoorthy, J. P. Baker and M. D. Amiridis, "Catalytic Oxidation of 1,2-Dichlorobenzene over $\mathrm{V}_{2} \mathrm{O}_{5} / \mathrm{TiO}_{2}$ Based Catalysts," Catalysis Today, Vol. 40, No. 1, 1998, pp. 39-46. doi:10.1016/S0920-5861(97)00117-X

[15] S. Krishnamoorthy, J. A. Rivas and M. D. Amiridis, "Catalytic Oxidation of 1,2-Dichlorobenzene over Supported Transition Metal Oxides," Journal of Catalysis, Vol. 193, No. 2, 2000, pp. 264-272. doi:10.1006/jcat.2000.2895

[16] Y. Liu, Z. Wei, Z. Feng, M. Luo, P. Ying and C. Li, "Oxidative Destruction of Chlorobenzene and o-Dichlorobenzene on a Highly Active Catalyst: $\mathrm{MnO}_{\mathrm{x}} / \mathrm{TiO}_{2}-\mathrm{Al}_{2} \mathrm{O}_{3}$," Journal of Catalysis, Vol. 202, No. 1, 2001, pp. 200-204. doi:10.1006/jcat.2001.3284

[17] P. Liljelind, J. Unsworth, O. Maaskant and S. Marklund, "Removal of Dioxins and Related Aromatic Hydrocarbons from Flue Gas Streams by Adsorption and Catalytic Destruction," Chemosphere, Vol. 42, No. 5-7, 2001, pp. 615-623. doi:10.1016/S0045-6535(00)00235-6

[18] R. Weber, T. Sakurai and H. Hagenmaier, "Low Temperature Decomposition of PCDD/PCDF, Chlorobenzenes and PAHs by $\mathrm{TiO}_{2}$-Based $\mathrm{V}_{2} \mathrm{O}_{5}-\mathrm{WO}_{3}$ Catalysts," Applied Catalysis B: Environmental, Vol. 20, No. 4, 1999, pp. 249-256. doi:10.1016/S0926-3373(98)00115-5

[19] M. Goemans, P. Clarysse, J. Joannès, P. De Clercq, S. Lenaerts, K. Matthys and K. Boels, "Catalytic $\mathrm{NO}_{\mathrm{x}}$ Reduction with Simultaneous Dioxin and Furan Oxidation," Chemosphere, Vol. 54, No. 9, 2004, pp. 1357-1365.

\section{doi:10.1016/S0045-6535(03)00255-8}

[20] J. Lichtenberger and M. D. Amiridis, "Catalytic Oxidation of Chlorinated Benzenes over $\mathrm{V}_{2} \mathrm{O}_{5} / \mathrm{TiO}_{2}$ Catalysts," Journal of Catalysis, Vol. 223, No. 2, 2004, pp. 296-308. doi:10.1016/j.jcat.2004.01.032

[21] K. Everaert and J. Baeyens, "Catalytic Combustion of Volatile Organic Compounds,” Journal of Hazardous Materials, Vol. 109, No. 1-3, 2004, pp. 113-139. doi:10.1016/j.jhazmat.2004.03.019

[22] A. Galvez, J. A. Conesa, I. Martin-Gullon and R. Font, "Interaction between Pollutants Produced in Sewage Sludge Combustion and Cement Raw Material," Chemosphere, Vol. 69, No. 3, 2007. pp. 387-394. doi:10.1016/j.chemosphere.2007.05.024

[23] A. Fullana, R. Font, J. A. Conesa and P. Blasco, "Evolution of Products in the Combustion of Scrap Tires in a Horizontal, Laboratory Scale Reactor," Environmental Science \& Technology, Vol. 34, No. 11, 2000, pp. 20922099. doi:10.1021/es990883y

[24] A. Fullana, J. A. Conesa, R. Font and S. Sidhu, "Formation and Destruction of Chlorinated Pollutants during Sewage Sludge Incineration,” Environmental Science \& Technology, Vol. 38, No. 10, 2004, pp. 2953-2958. doi:10.1021/es034896u

[25] B. Dellinger and P. H. Taylor, "Chemical Aspects of Combustion of Hazardous Wastes,” Central European Journal of Public Health, Vol. 6, 1998, pp. 79-87.

[26] A. Atal, Y. A. Levendis, J. Carlson, Y. Dunayevskiy and P. Vouros, "On the Survivability and Pyrosynthesis of PAH during Combustion of Pulverized Coal and Tire Crumb," Combustion and Flame, Vol. 110, No. 4, 1997, pp. 462-478. doi:10.1016/S0010-2180(97)00086-2

[27] H. Richter, T. G. Benish, O. A. Mazyar, W. H. Green and J. B. Howard, "Formation of Polycyclic Aromatic Hydrocarbons and Their Radicals in a Nearly Sooting Premixed Benzene Flame," Proceedings of the Combustion Institute, Vol. 28, No. 2, 2000, pp. 2609-2618. doi:10.1016/S0082-0784(00)80679-7

[28] X.-W. Zhang, S.-C. Shen, L. E. Yu, S. Kawi, K. Hi- dajat and K. Y. Simon Ng, "Oxidative Decomposition of Naphthalene by Supported Metal Catalysts," Applied Catalysis A: General, Vol. 250, No. 2, 2003, pp. 341-352. doi:10.1016/S0926-860X(03)00412-5 